\title{
Comunicación líquida en el pensamiento de Zygmunt Bauman: el espacio y el tiempo para la construcción de sentido
}

\section{Liquid communication in Zygmunt Bauman's thought: space and time for the construction of meaning \\ Comunicação líquida no pensamento de Zygmunt Bauman: espaço e tempo para a construção de sentido}

\author{
Margarita Mönckeberg1 \\ Universidad de los Andes (Chile) \\ mmonckeberg@gmail.com \\ Tomás Atarama Rojas ${ }^{2}$ \\ Universidad de Piura (Perú) \\ tomas.atarama@udep.edu.pe
}

Fecha de recepción: $x$ de mes de año

Fecha de recepción evaluador: 25 de febrero de 2020

\footnotetext{
${ }^{1}$ Margarita Mönckeberg Díaz es candidata a Doctora en Comunicación por la Universidad de los Andes (Chile). Magíster Académico en Comunicación por la Universidad de los Andes (Chile), Magíster en Humanidades por la Universidad Adolfo Ibáñez (Chile). Actualmente se desempeña como profesora en la Facultad de Comunicación de la Universidad de los Andes (Chile). Su investigación se centra en el Periodismo Narrativo, y en la línea de investigación de myth \& news. ORCID: https://orcid.org/0000-0002-4415-3645

${ }^{2}$ Tomás Atarama-Rojas es candidato a Doctor en Comunicación por la Universidad de los Andes (Chile). Magíster Académico en Comunicación por la Universidad de los Andes (Chile), Máster en Creación de Guiones Audiovisuales por la Universidad Internacional de La Rioja (España) y Licenciado en Comunicación por la Universidad de Piura (Perú). Actualmente se desempeña como profesor investigador de la Facultad de Comunicación de la Universidad de Piura (Perú). Su investigación se centra en la narrativa transmedia y el storytelling corporativo. ORCID: https://orcid.org/0000-0002-4430-3391
} 


\title{
Resumen
}

La investigación aborda el concepto de liquidez propuesto por Zygmunt Bauman y lo aplica al campo de la comunicación para encontrar las características que definen una comunicación líquida en la cultura contemporánea. Así, se destacan los conceptos de espacio y de tiempo como ejes claves para entender el paso a la modernidad líquida. Finalmente, se plantea que a través de la revalorización del espacio y el tiempo y de la comunicación como ritual se aporta significado al mensaje y se enriquece la comunicación y a los partícipes en ella, en orden a promover un sentido de comunidad.

Palabras clave: Zygmunt Bauman, modernidad líquida, comunicación líquida, comunicación, tiempo, espacio.

\begin{abstract}
The research studies the liquidity concept proposed by Zygmunt Bauman and applies it to the field of communication to find the characteristics that define a liquid communication in contemporary culture. Thus, the concepts of space and time stand out as key axes to understand the transition to liquid modernity. Finally, it is proposed that through the revaluation of space and time and communication as a ritual, meaning is given to the message and communication and participants in it are enriched, in order to promote a sense of community.
\end{abstract}

Keywords: Zygmunt Bauman, liquid modernity, liquid communication, communication, time, space.

\section{Resumo}

A pesquisa estuda o conceito de liquidez proposto por Zygmunt Bauman e o aplica ao campo da comunicação para encontrar as características que definem uma comunicação líquida na cultura contemporânea. Assim, os conceitos de espaço e tempo destacam-se como eixos-chave para entender a transição para a modernidade líquida. Por fim, propõese que, através da reavaliação do espaço e do tempo e da comunicação como ritual, seja dado significado à mensagem e à comunicação e aos participantes nela enriquecidos, a fim de promover um senso de comunidade.

Palavras-chave: Zygmunt Bauman, modernidade líquida, comunicação líquida, comunicação, tempo, espaço.

\section{Introducción}


Pensar la comunicación y sus nuevas manifestaciones y exigencias en una sociedad cada vez más compleja es una tarea fundamental; porque de estas reflexiones no solo se desprenden descripciones de lo que ocurre, sino, sobre todo, propuestas que procuran enriquecer las prácticas profesionales de la comunicación, como uno de los modos para mejorar la vida en comunidad y, con ello, fomentar el desarrollo de cada persona.

Así, en esta investigación se piensa la comunicación desde la categoría de liquidez propuesta por el sociólogo polaco Zygmunt Bauman (1925-2017), conocido como el padre de la modernidad líquida, con el objetivo de describir la comunicación líquida y establecer coordenadas de mejora para el ejercicio de la comunicación. Para alcanzar este objetivo, se analiza primero el paso de la modernidad sólida a la modernidad líquida, los rasgos de una y otra, y los eventos posibles que provocaron el cambio, para luego dilucidar el significado de esta metáfora. Luego, se abordan las dos coordenadas claves de este trabajo: el espacio y el tiempo. Para Bauman (2003), el cómo inciden ambas categorías en la vida cotidiana explican la aparición de una modernidad líquida, donde justamente la instantaneidad y la inmediatez han mermado el valor del tiempo y el espacio en las relaciones humanas.

Finalmente, se analizan las implicancias del tiempo y el espacio en la comunicación contemporánea; se apunta que es importante establecer relaciones que destaquen el valor del espacio y del tiempo para fortalecer los lazos; con esto, la comunicación puede recuperar el contenido y el significado que se traslada no solo en proceso de transmisión de un mensaje, sino también en las relaciones que se establecen entre los partícipes de la comunicación.

\section{El concepto de liquidez: de la fase sólida a la líquida}

Para entender la fase líquida es importante exponer, primero, los rasgos de la modernidad sólida. La primera característica de la modernidad sólida es la creencia en el progreso. A partir del siglo XVII ya no se mira imperiosamente atrás a la antigüedad clásica; la fe se deposita hacia adelante en un futuro mejor, el "tiempo de los nuevos comienzos" (Béjar, 2007, p. 9). El proyecto ilustrado, basado en el avance de la razón, centra la historia en las conquistas humanas. La teoría del progreso, esta "ilusión moderna", confía en la capacidad del hombre de hacer "que las cosas ocurran" y, por tanto, tiene en germen un contenido movilizador (Béjar, 2007). La modernidad sólida, entonces, se aferra a la intención de instaurar un orden mejor basado en la razón. Para sedimentar este orden, se hace necesario acabar con toda ambivalencia, todo caos, toda espontaneidad.

Esta creencia fue un respaldo grande para la decisión moderna de instalar un orden artificial: un proyecto que volvió sospechosa toda espontaneidad hasta que se comprobara su inocencia, que proscribió todo lo que no estaba prescrito explícitamente (Bauman, 2011c, p. 332). Si bien la teoría del progreso, el universalismo y la identidad establecida 
forman los rasgos principales de la modernidad sólida (Béjar, 2007), en términos baumanianos, la gran preocupación moderna es el orden y, a partir de ahí, la lucha constante contra la contingencia y la ambivalencia. Se entendía el orden como predictibilidad; entorno estable donde los sucesos no se producen al azar, regularidad; deseo de aplacar las incertidumbres; convertir lo descontrolado en accesible y manejable. Existe la creencia de que el orden no puede darse por descontado, que es preciso construirlo (Castaño Rodríguez, 2005). Y, mientras se construye, el sentimiento de ambivalencia crece "y es lo que más preocupa e inquieta en la era moderna, ya que, a diferencia de otros enemigos derrotados y dominados, su vigor crece con cada éxito de los poderes modernos" (Bauman, 2011c, p. 37). De este modo, el rol que tiene el orden en la modernidad tiene como base la inseguridad de su realización: "la conciencia moderna es la sospecha de su carácter no concluyente" (Castaño Rodríguez, 2005, p. 280).

Esta incertidumbre que en la modernidad se intenta erradicar, se impone como un sueño imposible. De este modo, la entendida postmodernidad puede ser explicada como un "estado mental" de la modernidad que lleva a comprender que, esos esfuerzos por imponer un orden perfecto en la sociedad, "no sólo han fracasado sino que estaban destinados al fracaso" (Castaño Rodríguez, 2005, p. 284). De este modo, "la postmodernidad es modernidad que acepta su propia imposibilidad" (Bauman, 2011c, p. 358). La postmodernidad es la toma de conciencia de la irrevocable instalación de la incertidumbre, la contingencia y la ambivalencia en el corazón de la vida social (Castaño Rodríguez, 2005). "El mundo postmoderno se prepara para soportar una vida bajo un estado de incertidumbre que es permanente e irreductible” (Bauman, 2001b, p. 32).

Cuando crece la indiferencia hacia un Estado capaz de promover un orden único y la falta de confianza hacia los esquemas globales, surge la postmodernidad como un “interés particular sui generis por la diversificación, escasa determinación y «confusión» permanentes del mundo" (Bauman, 2001b, p. 22). Lo postmoderno, entonces, no es lo contrario de lo moderno sino su rebasamiento (Vásquez Rocca, 2011); no es tampoco un tiempo definido específicamente sino una condición humana determinada, que supone una incredulidad en relación a los grandes relatos y las grandes utopías que intentan explicar globalmente toda la realidad. Se produce una fragmentación, una descomposición de esos grandes relatos, "las «identificaciones» con los grandes nombres, los héroes de la historia actual se hacen más difíciles. [...] Cada uno se ve remitido a sí mismo. Y cada uno sabe que sí mismo es poco" (Lyotard, 1987, p. 4).

Esta postmodernidad, donde las esperanzas en el futuro son reemplazadas por el síndrome de la novedad perpetua del presente (Lipovetsky \& Charles, 2014), es entendida por Bauman (2003) como la modernidad sin sus ilusiones; en otras palabras, como modernidad líquida, para distinguirla de la primera fase de la modernidad. Para explicar el concepto de modernidad líquida es necesario señalar algunas características generales de los "líquidos" que permitan comprender la analogía propuesta. "Los fluidos, por así decirlo, no se fijan al espacio ni se atan al tiempo" (Bauman, 2003, p. 8); estos se desplazan: fluyen, gotean, se filtran, se desbordan, se derraman. Es la fuerte movilidad de 
los fluidos lo que permite asociarlos a la idea de levedad: "Asociamos «levedad» o «liviandad» con movilidad e inconstancia. [...] Estas razones justifican que consideremos la «fluidez» o la «liquidez» como metáforas adecuadas para aprehender la naturaleza de la fase actual" (Bauman, 2003, p. 8).

En este ambiente evasivo y cambiante propio de los líquidos, el tiempo deja de percibirse como esa flecha que apunta hacia adelante (propia de la teoría del progreso de la modernidad), la vida comienza a experimentarse momento a momento, de modo transitorio, en constante cambio, sin descanso (Deuze, 2008). En este sentido, la existencia se percibe en un estado de flujo incesante, en un contexto siempre abierto a nuevas posibilidades (Bauman, 1995); una sociedad de eventos fugaces, efímeros, con una conciencia de la acelerada evanescencia del tiempo; un sentimiento de que la vida se acelera, sensación de atolondramiento que responde al miedo de "perderse algo" (Han, 2016); una ansiedad por experimentar que "las cosas fluyen demasiado deprisa como para que propicien esperanza alguna de darles alcance" (Bauman, 2015, p. 13). La vida se percibe de modo contingente, poco estable, lo que significa "vivir sin garantía, con una certidumbre provisional, [...] y siempre momentánea” (Bauman, 2011c, p. 313).

En esta continua renovación promovida por el mercado, es necesario tener la oportunidad de adoptar y deshacerse de identidades, de dedicar la propia vida a la colección de experiencias siempre nuevas y cada vez más estimulantes (Bauman, 2001a). La identidad ya no es adquirida, sino autoconstruida, con un "carácter continuo de no finitud, de carencia" (Béjar, 2007, p. 99). La vida líquida no puede mantener su forma por mucho tiempo (Bauman, 2005b), estas identidades cambian antes de consolidar hábitos y rutinas, las personas se sienten siempre en movimiento, incluso cuando no lo están (Deuze, 2008); el pensamiento se hace rápido, la tarea de sopesar teorías y argumentos se dificulta.

En la modernidad líquida, el valor del universalismo ilustrado es sustituido por un relativismo cognitivo y moral (Béjar, 2007); la sociedad ya no se percibe como "una propiedad común de sus miembros, como una empresa en la que todos pueden contribuir" (Béjar, 2007, p. 97); el sentido de pertenencia y arraigo fiel y duradero a instituciones sociales como partidos políticos, instituciones religiosas, asociaciones voluntarias, entre otras, pierde solidez (Putnam, 2003): no es que las personas hayan decidido no participar más, sino que deciden hacerlo cuando sienten que quieren estar; cuando consideran que su membresía aporta al postulado que se tiene en ese momento (Deuze, 2008).

Desde la realidad virtual, esta forma de vida líquida ha sido descrita por Schudson con la figura del monitorial citizen, cuya actitud hacia la abrumadora cantidad de información suscitada en la web, es de constante monitoreo, escaneo de las distintas informaciones. Nuevamente, no es que el individuo ya no esté interesado, sino que "compromete su tiempo y su energía en sus propios términos" (Deuze, 2008, p. 852). Estos términos son cambiantes y fluidos, y por tanto las lealtades a comunidades y medios de comunicación, tienden a ser volátiles; no estables en el tiempo. 
La modernidad líquida, entendida por Lipovetsky \& Charles (2014) como hipermodernidad, es propensa al cambio permanente, ya que "cuando menos previsible es el futuro, más necesidad tenemos de ser móviles, maleables, reactivos" (Lipovetsky \& Charles, 2014, p. 60), de acuerdo con la cultura del más aprisa y del siempre más. Lipovetsky \& Charles (2014) explica que esta sociedad que anhela estar abierta siempre al cambio, que exige de parte del individuo estar en permanente movimiento para mantener esas opciones abiertas, provoca un estado de incertidumbre y ambivalencia continuo. El individuo añora -en un futuro hipotético- más estabilidad, menos aceleramiento, más certezas, pero, al mismo tiempo, le aterra la opción de quedarse atado, fijo, y perder esa libertad de movimiento.

\section{Relaciones de tiempo y espacio: cambios y consecuencias}

A partir de la modernidad y con la llegada de las telecomunicaciones, la relación vital espacio-temporal se rompe. Esta ruptura, agudizada por el fenómeno de la instantaneidad, es el ingrediente esencial de la metáfora baumaniana de la liquidez. Y es a partir de esta realidad que se desencadenan las consecuencias líquidas en los variados ámbitos sociales del ser humano y de su vida en comunidad (la fragilidad de los vínculos y compromisos, la formación de comunidades efímeras, relaciones contingentes de corto plazo, identidades mudables, desvalorización de las tradiciones locales).

Antes del advenimiento de las telecomunicaciones, un sitio determinado estaba lejos y por tanto tomaba tiempo alcanzarlo, o viceversa, un lugar quedaba cerca e implicaba poco tiempo llegar hasta él: este era un binomio espacio-temporal. En el momento en que la distancia recorrida pasó a depender de la tecnología, los límites de la velocidad del movimiento pudieron transgredirse. A partir de este punto, la relación entre el espacio y el tiempo es mutable, no determinada y variable (Bauman, 2003). La llegada de las telecomunicaciones es el momento de cambio a la sociedad líquida, cuyo hito clave es la nueva relación entre el tiempo y el espacio.

De este modo, "los movimientos acelerados significaban espacios más grandes, y acelerar los movimientos era la única manera de agrandar el espacio" (Bauman, 2003, p. 120). Para la modernidad sólida el espacio fue una de sus mayores obsesiones, fue la época de la conquista territorial, donde la riqueza y el poder se arraigaban firmemente en la tierra, dependían del tamaño, estaban “«encarnados» y fijos, atados al acero y el concreto" (Bauman, 2003, p. 123). Al producirse una aceleración cada vez mayor por el ansia de conquista de ese espacio, se alcanzó más tarde -a través de la tecnología- el fenómeno de la instantaneidad; propio de la modernidad líquida. Así, la percepción y experiencia actual y cotidiana de aceleramiento y falta de tiempo, está estrechamente relacionada a los cambios acaecidos en los procesos comunicativos a partir del desarrollo de las telecomunicaciones. De este modo la distancia espacial dejó de necesitar distancia temporal, "la información podía trasmitirse a través de vastas distancias con relativamente poco retraso" (Thompson, 1998, p. 53). 
Así, adquirió relevancia la lógica del tiempo breve, que ha posibilitado el intercambio comunicacional en "tiempo real", donde la sensación de inmediatez y simultaneidad han devaluado de modo progresivo las formas de la espera y de la actitud de demorarse (Lipovetsky \& Charles, 2014). En esta misma lógica, la información preferida -aquella que en general es más proclive a captar la atención humana- es la más breve: "oraciones en lugar de argumentos elaborados, palabras de moda en lugar de oraciones, fragmentos sonoros en lugar de palabras" (Bauman, 2011a, p. 125). Sufrimos del síndrome de la impaciencia, donde "toda dilación o espera se ha transformado en un estigma de inferioridad" (Bauman, 2008, p. 22).

Lo que verdaderamente señala la llegada de la instantaneidad es "la ausencia del tiempo como factor del acontecimiento y, por consiguiente, su ausencia como elemento en el cálculo del valor" (Bauman, 2003, p. 126). El transporte de información se comportó especialmente sensible con la llegada de la instantaneidad: ahora se requiere de poco o ningún desplazamiento de cuerpos físicos (Bauman, 2013).

Esto ha provocado que el mundo, tal como lo experimentan las personas, no solo se está haciendo más pequeño, sino que, a su vez, pareciera que se hace más grande. Con la reducción del instante a magnitud cero, los indicadores de espacio y tiempo pierden importancia, la situación geográfica disminuye su relevancia, "nos volvemos nómadas, turistas, siempre conectados [...] estamos en movimiento en un sentido profundo" (Bauman, 2013, p. 104). Se produce una compresión espacio-temporal donde toda distancia está en condiciones de ser comprimida. La señal de nuestro tiempo, entonces, ya no es el desplazamiento físico, en un entorno conocido y un territorio consistente, sino el flujo de informaciones a través de redes globales conectadas entre sí, que han debilitado el tradicional valor del territorio (Sánchez Capdequí, 2006).

Este fenómeno de instantaneidad ha producido una nueva polaridad: por una parte están quienes pueden desplazarse -las llamadas "élites móviles"- y, por otra, el resto del mundo local. Lo que los distingue es su grado de movilidad; al tiempo que crece la distancia e incomunicación entre ambos. "En la modernidad «líquida» dominan los más elusivos, los que tienen libertad para moverse a su antojo" (Bauman, 2013, p. 129).

Luego de abordar las coordenadas espacio-temporales propias de la modernidad sólida y su paso hacia la modernidad líquida, y esbozar sus principales consecuencias, se revisan a continuación cuáles son las consecuencias humanas de esta compresión espaciotemporal, las implicancias en la configuración humana de los tipos que cohabitan el mundo líquido; diferente de aquellos habitantes de la fase sólida. Para esto, se desarrollan las metáforas temporales del peregrino, el turista y el vagabundo. Los turistas y los vagabundos son denominados por Bauman (2005a) como los "nómadas posmodernos", y los diferencia de sus predecesores: los "peregrinos modernos". Los nómadas están en constante movimiento, los lugares que atraviesan no son más que estaciones (Bauman, 2005a), sin embargo considera más precisa la metáfora del vagabundo y del turista, ya que los nómadas "siguen un orden de las cosas", se mueven de modo regular; los otros, en cambio, no saben cuánto tiempo permanecerán en un sitio, fijan su destino a medida 
que van avanzando, y no saben cuándo se detendrán, ni por cuánto tiempo, son "nómadas sin itinerarios" (Bauman, 2005a, p. 273).

Antes que se produjera la destemporalización del espacio social, que es uno de los factores claves en el cambio de la modernidad sólida a la modernidad líquida, el tiempo tenía una dirección, al igual que cualquier trayecto en el espacio (Bauman, 2001b). Los hombres modernos vivían en un espacio-tiempo estructurado. Las personas podían sentirse desorientadas, pero rápidamente podían volver a encontrarse en el camino. Esta estructura estaba dada a priori a cualquier acción humana, permanecía estable. "La diferencia entre perderse y llegar estaba hecha de conocimiento y determinación: el conocimiento de la estructura espacio-temporal y la determinación de seguir el itinerario" (Bauman, 2001b, p. 111). Bastaba seguir el camino paso a paso, un logro tras otro. Este era el mundo de los peregrinos que forjaban su proyecto de vida en el tiempo; un tiempo que debía durar toda la vida.

Esto no significa que el hombre moderno fuese consciente en su vida cotidiana del conocimiento de esta estructura espacio-temporal; solo se intenta advertir que el hombre contemporáneo, al observar retrospectivamente al hombre moderno, se da cuenta de esa experiencia anterior: "Lo que pensamos que el pasado tenía es lo que sabemos que nosotros no tenemos" (Bauman, 2001b, p. 112). El mundo hecho de acciones y objetos duraderos ha sido reemplazado por el de productos, comunidades e identidades cambiantes, contingentes, diseñadas para el corto plazo y de posibilidades "siempre abiertas". En un mundo así, "las identidades pueden cambiarse como quien cambia de vestido" (Bauman, 2001b, p. 113) y la estrategia de vivir la vida como peregrinación, se hace muy poco probable.

En la modernidad líquida, los individuos son invitados a estar continuamente en movimiento sin la esperanza de consolidar ninguna posición (Durán, 2014); moverse es el camino y también la meta, de este modo, la experiencia cotidiana carece de continuidad, de trayectoria histórica, "de una perspectiva arraigada en el tiempo que le dé sentido" (Bauman, 2009, p. 80). Esto implica en la práctica negarse a asumir una posición fija, atarse a lugares o proyectos de largo alcance, no "jurar" constancia a nada ni a nadie.

Bauman (1995) explica que cuando la flecha que estructuraba el tiempo moderno hacia adelante quedó desprovista de su capacidad de vector; el tiempo dejó de estructurar el espacio; en el terreno ya no existe un ir hacia atrás o hacia delante: solo importa la habilidad de moverse y no quedarse fijo en un lugar. La imagen del turista refleja muy bien a este nuevo tipo postmoderno: no pertenece al lugar que está visitando, sabe estar dentro y fuera de ese sitio al mismo tiempo. Lo importante en la vida del turista es estar en movimiento, no llegar al destino; a diferencia de los anteriores peregrinos modernos. Mientras dura el movimiento (que no cesará) no hay imágenes pertenecientes al futuro que permitan comprender y otorgar significado a ese presente: "cada presente sucesivo [...] debe explicarse a sí mismo en sus propios términos y proporcionar su propia clave para leer su sentido" (Bauman, 2001b, p. 115). Se trata entonces de una temporalidad puntillista de presentes sin un proceso histórico, narrativo (Bauman, 2007). 
El turista no contrae obligaciones de largo plazo, sus paradas en los distintos lugares se parecen más al camping que al domicilio, no "echa raíces" y, si es que echa alguna, solo lo hace de modo superficial; todo esto proporciona al turista la sensación de "tener el control" (Bauman, 2001b). Esta atención fluctuante y el punto de vista cambiante, esta posibilidad de conectar y desconectar, es entonces la nueva estructura del hombre contemporáneo.

Junto a la figura del turista como la metáfora temporal contemporánea, se nombró la figura del vagabundo. Tanto este último como el turista son extraterritoriales, se mueven "a través de espacios donde otros habitan" (Bauman, 2005a, p. 275), tienen encuentros breves o desencuentros con los locales. No obstante, "los turistas viajan porque quieren; los vagabundos porque no tienen otra opción” (Bauman, 2001b, p. 118). Si los turistas se mueven constantemente en busca de nuevas experiencias exóticas y cada vez más emocionantes porque les parece atractivo; los vagabundos, en cambio, van de un lugar a otro, porque el mundo se les presenta cada vez más inhóspito. La oposición entre vagabundos y turistas constituye la división más importante dentro de la sociedad contemporánea: "Todos nosotros nos hallamos repartidos sobre un continuo que se entiende entre los polos del «perfecto turista» y del «vagabundo sin remedio»" (Bauman, $2001 b$, p. 118) y, nuestra posición entre ambos polos se sitúa en función del grado de libertad que tenemos para elegir nuestros itinerarios de vida. Es necesario aclarar que la figura del turista y del vagabundo se trata de metáforas postmodernas, es decir, se puede ser un turista o un vagabundo en sentido figurado; sin viajar físicamente muy lejos.

La metáfora temporal baumaniana del turista y el peregrino es explicada a su vez por el filósofo surcoreano Byung-Chul Han, quien distingue ambas figuras por la presencia o ausencia de narrativa, en una y otra, respectivamente. "La peregrinación es un suceso narrativo. Por eso, el camino de peregrinación no es un pasadizo que haya de recorrerse con tanta rapidez como sea posible, es más bien un camino rico en semántica" (Han, 2013, p. 62). Por contraste, el turista "se mantiene en el presente, aquí y ahora. No está en camino en sentido auténtico. Los caminos no tienen significatividad. [...] Al turista le es extraña la semántica rica, la narratividad del camino" (Han, 2013, p. 63).

En el mundo del turista contemporáneo, el tiempo se ha atomizado; no hay nada que una los acontecimientos entre sí, generando una relación, una duración. El tiempo se percibe acelerado porque "sin ningún apoyo ni centro de gravedad sobre el que sostenerse, se precipita, transcurre imparable" (Han, 2016, p. 22). El tiempo del turista es un tiempo no narrativo, ya que la narración no es el resultado automático de una suma de sucesos; sino que es selectiva, configurativa, "presenta una síntesis particular que se debe al sentido (Sinn). Una larga enumeración de acontecimientos no genera una tensión en la narración" (Han, 2016, p. 26). Componer una trama narrativa consiste precisamente en una síntesis de lo heterogéneo, "en hacer surgir lo inteligible de lo accidental, lo universal de lo singular, lo necesario o lo verosímil de lo episódico" (Ricoeur, 1987, p. 41). 
En el tiempo atomizado del turista -a diferencia del guiado del peregrino- "todos los momentos son iguales entre sí. No hay nada que distinga un momento del otro" (Han, 2016, p. 16). De este modo, la vida contemporánea transcurre de modo episódica, y la esencia del episodio es que "no deja rastros: la vida vivida como una sucesión de episodios es una vida libre de la preocupación de las consecuencias" (Bauman, 1995, p. 5). Se trata de un acontecimiento que no tiene implicancias más allá de su propia duración; está cerrado sobre sí mismo, no continuará, “irrumpe en la historia sin formar parte de ella" (Bauman, 2001b, p. 116). En este contexto, el individuo busca coleccionar experiencias de efectos inmediatos, con el fin de estar abierto a las próximas posibilidades que aparezcan.

\section{Una aproximación a la comunicación líquida y sus remedios}

Zygmunt Bauman no asigna un rol performativo de modo directo a la comunicación dentro de la sociedad contemporánea; si bien roza diversas temáticas relacionadas a ella, no se detiene a describirla de modo sistemático y explícito. En esta investigación se recoge los trazos de liquidez en la comunicación, con el objetivo de sintetizarlos y proyectar con ellos el concepto de comunicación líquida. Una vez definido este concepto, se delinearán algunos énfasis y aportes de la comunicación en la sociedad actual.

Comprender la comunicación es el desafío de la Teoría de la Comunicación (Martín Algarra, 2009); objetivo arduo en el que existe amplia coincidencia en la dificultad que esto significa, ya que estamos frente a un fenómeno complejo protagonista de toda la vida de los seres humanos (Craig, 1999). No obstante, esta dificultad se simplifica al comprender la comunicación desde dos grandes visiones: la transmisión y el ritual, descritos por James W. Carey (2009). Mientras Bauman, desde la Sociología, advierte los cambios acaecidos en la postmodernidad y acuña el concepto de liquidez; al mismo tiempo, Carey, desde los estudios de Comunicación, describe la comunicación en torno a estos dos grandes paradigmas y señala la necesidad de otorgar énfasis al segundo de ellos (el de ritual).

La visión de la transmisión entiende la comunicación como extensión de mensajes en el espacio; mientras que la visión de ritual se refiere especialmente a la relación de la comunicación y sus raíces compartidas con los términos comunidad, comunión, común, es decir, comprende la comunicación como integración, vinculación, tradiciones y continuidad (Carey, 2009). Para este autor, no se trata de reflexiones excluyentes entre sí, sino complementarias; destaca que a partir de los años 90 se privilegia la visión de la transmisión en desmedro de la visión de ritual y, por ende, su propuesta es enfatizar esta segunda visión, ya que, desde su perspectiva, siguiendo a Dewey, la sociedad no sólo existe por la transmisión sino en la transmisión; es decir, no sólo "a través de la transmisión de mensajes en el espacio sino a través del mantenimiento de la sociedad en el tiempo" (Carey, 2009, p. 15). Por tanto, desde su óptica, no existe una visión negativa 
y otra positiva, sino que ambas se necesitan. A su vez, advierte la importancia de no sacralizar la visión de la transmisión a través de las tecnologías, ya que no se trata solo de transmitir información, sino de examinar el contenido de esta, su orden simbólico, “aquello que está por debajo del orden de las cosas" (Carey, 2009, p. 15).

El paradigma de la transmisión se relaciona especialmente con la necesidad de compartir una experiencia del mundo, de un individuo que conoce y vive una realidad y desea darla a conocer; hacer co-partícipe a otra persona o grupo que no cuenta inicialmente con esa vivencia. De este modo, el "experimentado" le muestra "al no experimentado" su realidad. En este paradigma, por tanto, a la hora de definir el concepto comunicativo, lo que ocurre con los participantes es de menor relevancia que el proceso que se lleva a cabo (Martín Algarra, 2009).

La visión de ritual, en cambio, entiende que la comunicación tiene que ver primeramente con la "dimensión social de la vida humana, con la existencia de un mundo común compartido que hace que los copartícipes en la comunicación sean parte de una misma realidad" (Martín Algarra, 2009, p. 75). Está relacionado a un sentido de pertenencia, a valores y tradiciones compartidas. Desde la visión de ritual, al examinar el contenido de la comunicación, el significado de sus símbolos, se promueve la posibilidad de "extender la conversación humana a través de la comprensión de lo que los otros están diciendo" (Carey, 2009, p. vii).

Bauman (2005b) sostiene que las antiguas comunidades eran densas en contenido, relaciones, tradiciones y ritos, que les permitían mantenerse integrados y cohesionados. Todos estos vínculos se forjaban por la comunicación directa entre los miembros de aquella comunidad. Con la llegada de las telecomunicaciones y luego con el fenómeno de la instantaneidad esa comunicación intracomunitaria perdió "sus ventajas respecto del intercambio intercomunitario" (Bauman, 2002, p. 41). Es decir, estar dentro o fuera, cerca o lejos perdió parte de su significado antes tan diferente.

Entonces la comunicación sólida, si bien no es definida por Bauman, se puede comprender -recogiendo el aporte de Carey (2009)- como aquella comunicación entendida en términos de transporte, transmisión, capaz de alcanzar grandes distancias, con el objetivo de lograr unidad entre localidades distantes en el espacio, y diferentes desde la perspectiva social y cultural. Bauman (2003) sostiene que en la modernidad sólida "el espacio y el tiempo se separan de la práctica vital" (p. 14), y el espacio se convierte en el valor y el tiempo en la herramienta para superar los límites del espacio y acortar las distancias. La comunicación sólida entonces se focalizó en la conquista de este espacio intentando acortar, vía la tecnología y el transporte, al máximo posible la distancia entre los emisores y receptores. Este énfasis provocó una aceleración cada vez mayor, hasta alcanzar el fenómeno de la instantaneidad propio de la modernidad líquida.

La idea de comunicación líquida es posible circunscribirla, de acuerdo con las características descritas por Carey (2009), en su origen y hasta hoy, en la visión de la comunicación como transmisión; más que en su idea de ritual e integración. Al producirse el quiebre de la relación vital entre espacio y tiempo, una de las características de la 
comunicación líquida es que, a partir de ese momento, "los mensajes flotan libres de sus transportadores" (Bauman, 2013, p. 29), es decir, se produce una destemporalización del espacio social y de este modo "la traslación y el posicionamiento físico de los cuerpos en el espacio físico son menos necesarios que nunca para el reordenamiento de significados y relaciones" (Bauman, 2013, p. 29).

En términos comunicativos, entonces, el movimiento de la información sufrió una aceleración mayor incluso que la de los cuerpos o los cambios de los cuales informaba (Bauman, 2013, p. 24). Peters (2003) argumenta que la consecuencia clave de estos cambios tecnológicos fue la "emancipación de la comunicación de sus fundamentos guía en el mundo de la materia” (p. 398). Comunicación vertiginosa, veloz, ansiosa de llegar a más y más aprisa; un tipo de comunicación donde -con la reducción del instante a magnitud cero- las coordenadas de espacio y tiempo pierden importancia. Esta disociación espacio-temporal y esta pérdida de significancia de ambas coordenadas son una realidad esencial que explica las características propias de la comunicación líquida.

La comunicación en el contexto postmoderno de instantaneidad supone la existencia de un emisor y un receptor que se encuentran a menos de una fracción de segundo de distancia. La constatación de este hecho no implica, sin embargo, que esta distancia mínima e imperceptible no exista. Si el tiempo y espacio de comunicación han dejado de ser referentes, el contexto en el que se origina y luego se recibe el mensaje ha dejado, a su vez, de ser relevante en la consideración cotidiana del proceso comunicativo. No obstante, aunque el tiempo entre la emisión y la recepción del mensaje se reduzcan hoy casi a cero, no debe por esto dejar de comprenderse que los contextos de emisión y recepción son diferentes. Esta afirmación es explicada por Peters (2003), quien sostiene que "toda comunicación que recibimos de otra persona viene del pasado incluso, en una discusión cara a cara, existe un mínimo retraso entre la partida y la llegada del mensaje" (Peters, 2003, p. 408).

Tanto la emisión como la recepción de un mensaje son, por tanto, actividades situacionales (Thompson, 1998). Se origina un mensaje en una situación, en un contexto socio-emocional, histórico y cultural específico, y luego se decodifica por uno o más individuos; cada uno de ellos, a su vez, desde su situación personal y cultural también específica. En ese traslado del mensaje de un contexto a otro, se produce fundamentalmente un proceso de interpretación (hermenéutico), que es necesario considerar, desde la comunicación entendida como ritual, en el estudio del proceso comunicativo: "Quienes reciben los productos mediáticos en otro contexto, en otra situación, se ven envueltos en un proceso de interpretación a través del cual dan sentido a esos productos" (Thompson, 1998, p. 66).

La ausencia del tiempo como factor del acontecimiento, como elemento en el cálculo de su valor (Bauman, 2003, p. 126) tiene como consecuencia una pérdida de significancia de contextos particulares, culturales, comunitarios, todos ellos atados a un tiempo y un espacio específico. La comunicación, de esta forma, se centra en el proceso comunicativo, en que este sea más veloz y eficiente; más que en las condiciones humanas 
propias de quien emite y recibe y de aquello que sucede en el mensaje durante el proceso de transmisión, debido a la influencia de esos contextos locales (Martín Algarra, 2009).

Como consecuencia de lo anterior, se desarrolla en el panorama postmoderno el fenómeno de la glocalización. Para Bauman (2003), la glocalización es el proceso de despojar de su significado a lo local y añadirle simultáneamente otro significado diferente. Pero, despojar a lo local de su significado implica que sus carencias, pero también sus potencialidades y su plenitud "ya no se consideran como algo que le es propio" (Bauman, 2015, p. 208) y hay otras fuerzas extraterritoriales que disponen finalmente el significado de los eventos.

De este modo, estos significados pasan a ser extraterritoriales, independientes de sus realidades locales. Así, un mensaje local puede tener un alcance global, o uno global tener una repercusión local. El espacio geográfico ya no es un obstáculo, y el tiempo tampoco es un elemento por considerar; sin embargo, los valores, las creencias, los símbolos que construye y comparte cada persona a través de la comunicación representan una historia, es decir, están estructurados en el tiempo, aunque se proyecten en el futuro o se transmitan de modo simultáneo cuentan con un pasado, con una trayectoria que les da su significancia. En la comunicación líquida que no valora como factor del acontecimiento el tiempo, se pierde contenido y significancia. De este modo, en este contexto, la semántica de la interacción se empobrece, ya que se valora más la transitoriedad que la duración propia de valores, tradiciones, símbolos que se dan en un tiempo continuo (Bauman, 2003).

Para Carey (2009), considerar la comunicación sólo en términos de transmisión y no de ritual implica "desligar la cultura de la localidad en la que fue creada, para reubicarla a distancia y readaptarla en entornos nuevos y poco confortables" (p. 2). Sin embargo, esta vasta extensión posible de abarcar gracias a las tecnologías no es determinante: "Nunca podrán desligar los instintos y las necesidades de un pasado histórico. Nos encontramos poseídos por aquello a lo cual no podemos renunciar: rituales y narraciones que se encuentran en el estricto sentido antropológico" (Carey, 2009, p. 2). De este modo, las nuevas tecnologías si bien facilitan la extensión en el espacio, "crean tensión en los cimientos comunes de la sociedad que sólo pueden ser mantenidos por el lenguaje del tiempo y los vínculos, el apego, y las estructuras locales" (Carey, 2009, p. xix).

Los problemas de comunicación están relacionados a los problemas de la comunidad, a los problemas que rodean los tipos de comunidad que se crean y en las que se vive. Al comprender el entorno sociológico se comprende, a su vez, las formas líquidas de interacción actuales. La comunicación contemporánea corresponde a las características descritas en el escenario líquido de Bauman. La compresión espaciotemporal trajo consigo nuevas formas de vivir, de concebir la realidad, y por tanto de comunicarse.

En este panorama líquido, las identidades son frágiles, el nivel de compromiso es débil, los proyectos de largo alcance son desplazados por aquellos disponibles "aquí y 
ahora"; el mundo se percibe como una multiplicidad de ofertas que es necesario alcanzar; la lógica de la urgencia es la que funciona, lo continuo y durable ya no son signos de perfeccionamiento, se instala un ritmo acelerado e imparable; importa ser flexibles y capaces de reciclarse de acuerdo a las nuevas formas de vida que aparecen constantemente. En esta realidad líquida, la ansiedad y la ambivalencia se instalan en el corazón de este hombre líquido que quiere, por un lado contar con algún grado de certezas y seguridad en este ambiente móvil, efímero y contingente pero, a su vez, no quiere atarse, ni comprometerse en el tiempo, ya que para él es fundamental no perder la posibilidad de seguir en movimiento para alcanzar las nuevas opciones que presente este escenario volátil. Individuos que se reúnen en torno a comunidades frágiles, de vínculos débiles, pasajeros, de encuentros superficiales y transitorios; de emociones compartidas, cambiantes y momentáneas. Dado este escenario, la comunicación no puede darse de espaldas a este contexto; sino, por el contrario, permearse con ese entorno y responder a él.

Bauman (2011a) observa cómo desde el ámbito de los medios de comunicación existe un intento desesperado por captar la atención y la fidelidad de este grupo tan difícil de asir, que es denominado por Scolari (2013, p. 219) como audiencia líquida, que se caracteriza por ser móvil, mudable en sus preferencias y compromisos, vinculado a emociones de por sí poco durables. La estrategia utilizada por los medios es causar el máximo impacto y una instantánea obsolescencia, ya que para capturar la atención los contenidos deben impactar y, al mismo tiempo, contar con una duración efímera "porque están obligados a hacerles lugar a nuevos impactos" (Bauman, 2011b, p. 201). En este esfuerzo, el precio es el encogimiento del contenido y la drástica reducción de su significación (Bauman, 2011a, p. 125); ya que la información deja de ser informativa y pasa a ser deformativa: "la comunicación ya no es comunicativa, sino acumulativa" (Han, 2013, p. 89).

\section{A modo de conclusión: recuperar el sentido de la comunicación}

Bauman (2015) asigna de modo indirecto un rol social a la comunicación como facilitadora de la comprensión entre estos unos y estos otros (con rostros personalizados). A través de la comunicación, se permite al hombre "vivir el uno con y para el Otro" (Bauman, 2015, p. 81), en el tiempo, ya que "sólo entre individuos considerados en su totalidad la comunicación puede ser verdaderamente continua" (Bauman, 1995, p. 51). Es decir, la comunicación es la vía (a través de las emociones orientadas y vinculadas al compromiso con un Otro) que permite la comprensión, que facilita un encuentro comprometido y responsable. Esta comunicación que mueve hacia una relación entre personas con rostros definidos es la forma de comunicación que puede ser estable en el tiempo, es decir, navegar con más certidumbre en el contingente panorama líquido. 
Así, una de las tareas de las profesiones de la comunicación es no ahogarse en la pretensión de instantaneidad, sino poner en valor el tiempo, no solo en la transmisión o el consumo, sino también en la producción de contenidos que han de nacer de un conocimiento profundo del espacio que se habita, para ser cercano a las personas que se reconocen en él. A partir de aquí, se debe aprovechar las tecnologías para hacer que el mensaje, sin perder su génesis espacial, llegue al mayor público posible, para transmitir el contenido generado. Cuando se tiene en cuenta que todo producto de comunicación es hecho por personas, trata sobre cuestiones que afectan a personas y se dirige a personas, entonces es posible poner en valor una comunicación más humana, capaz de dejar algo duradero y con sentido (Atarama-Rojas, 2011), esto es, destacar el carácter de ritual de la comunicación.

En esta misma línea y coincidiendo con la propuesta baumaniana, Martín-Algarra, Torregrosa y Serrano (2010) ponen en el centro de la comunicación -desde la visión de la comunicación como ritual- el rol de integración en las circunstancias actuales: "cuando el tiempo y el espacio no se reducen a la dimensión física, el sentido de pertenencia que genera la comunicación adquiere un mayor protagonismo en la vida social" (p. 81). Y es esto lo que da sentido a la comunicación: "la existencia de una comunidad que tiene en la comunicación su posibilidad de cohesión, comprensión y comunicación” (p. 81).

La comunicación debe ser practicada con el sentido de ritual; en contraste a la visión de comunicación como transmisión. Ésta última entiende comunicación con la figura de un comunicador haciendo algo (persuadiendo, promoviendo) a otro. La comunicación entendida como ritual, en cambio, supone un comunicador haciendo algo con alguien. (Starck \& Kruckeberg, 2001, p. 58)

Estos autores argumentan que el sentido de la profesión del comunicador es el intento de restaurar y mantener este sentido de comunidad que se ha ido perdiendo debido al desarrollo y la primacía del moderno concepto de comunicación entendido como transporte, transmisión. Starck y Kruckeberg (2001) señalan que las corporaciones forjarán un sentido de comunidad, en la medida que tengan en mente todos los componentes ambientales; esto es, todos aquellos grupos que afectan a la organización y aquellos que se ven afectados por ella. En términos de comunicación, afirman que el foco está en la atención a las dimensiones de la interacción entre estos distintos grupos; buscando relaciones sostenibles en el tiempo, basadas en la responsabilidad y el servicio a la sociedad.

Esta función social de restaurar y mantener un sentido de comunidad en el tiempo, de acuerdo al contexto contemporáneo descrito por Bauman (2003), es un desafío complejo; el concepto mismo de comunidad, de sentido de comunidad (entendido como sentido de pertenencia) ha cambiado de significado y se ha tornado débil, frágil y contingente. Por esto, resulta necesario revalorizar y fortalecer el vínculo de la relación, dando relevancia a la visión de la comunicación como ritual donde el comunicador no está haciendo o diciéndole algo a alguien, sino que está ejecutando esa acción con alguien.

Bauman (1995), al describir los tipos de encuentros contemporáneos entre las personas, sostiene que se caracterizan por la presencia de individuos que se encuentran al 
lado del Otro; en una co-presencia. Sin embargo, advierte que existe otra forma de relacionarse que implica estar con y para el Otro (being-for), y entonces -al trascender ese estar al lado e involucrarse con la totalidad de la persona- la comunicación puede ser continua. A su vez, antes este panorama líquido, Starck y Kruckeberg (2001) coinciden con la propuesta baumaniana, y señalan que las instituciones tienen una oportunidad inusual de responder a estos cambios promoviendo relaciones de mutuo beneficio para las organizaciones y la sociedad, en la medida en que exista una reconceptualización sobre "cómo las corporaciones se comunican with más que to" con los diversos componentes ambientales que configuran el entorno de la organización.

\section{Referencias bibliográficas}

Atarama-Rojas, T. (2011). El reconocimiento de la persona como requisito para el ejercicio prudente de la actividad informativa. ComHumanitas, 3(3), 23-36. Recuperado de http://www.comhumanitas.org/index.php/comhumanitas/article/view/3

Bauman, Z. (1995). Life in fragments: Essays in postmodern morality. Oxford: Blackwell Publisher.

Bauman, Z. (2001a). Community. Seeking safety in an insecure world. Cambridge: Polity Press.

Bauman, Z. (2001b). La posmodernidad y sus descontentos. Madrid: Akal.

Bauman, Z. (2002). La cultura como praxis. Barcelona: Paidós.

Bauman, Z. (2003). Modernidad líquida. México: Fondo de Cultura Económica.

Bauman, Z. (2005a). Ética posmoderna. México: Siglo XXI.

Bauman, Z. (2005b). Identidad. Buenos Aires: Losada.

Bauman, Z. (2007). Tiempos líquidos: vivir en una época de incertidumbre. Barcelona: Tusquets Editores.

Bauman, Z. (2008). Los retos de la educación en la modernidad líquida. Barcelona: Gedisa.

Bauman, Z. (2009). El arte de la vida: De la vida como obra de arte. España: Grupo Planeta.

Bauman, Z. (2011a). Daños colaterales. Desigualdades sociales en la era global. Madrid: Fondo de Cultura Económica.

Bauman, Z. (2011b). La sociedad sitiada. Buenos Aires: Fondo de Cultura Económica.

Bauman, Z. (2011c). Modernidad y ambivalencia. Barcelona: Anthropos Editorial. 
Bauman, Z. (2013). La globalización: Consecuencias humanas. Buenos Aires: Fondo de Cultura Económica.

Bauman, Z. (2015). Esto no es un diario. D.F. México: Paidós.

Béjar, H. (2007). Identidades inciertas: Zygmunt Bauman. Barcelona: Herder.

Carey, J. W. (2009). Communication as culture, revised edition: Essays on media and society. London \& New York: Routledge.

Castaño Rodríguez, P. (2005). Zygmunt Bauman y el problema del orden: una mirada sociológica a la modernidad y la posmodernidad. Revista Colombiana de Sociología, (24), 275-296.

Craig, R. (1999). Communication Theory as a Field. Communication Theory, 9(2), 119161.

Deuze, M. (2008). The changing context of news work: Liquid journalism and monitorial citizenship. International Journal of Communication, 2(5), 848-865.

Han, B. C. (2013). La sociedad de la transparencia. Barcelona: Herder.

Han, B. C. (2016). El aroma del tiempo. Un ensayo filosófico sobre el arte de demorarse. Barcelona: Herder.

Lipovetsky, G., \& Charles, S. (2014). Los tiempos hipermodernos. Madrid: Anagrama.

Lyotard, J. F. (1987). La condición posmoderna: informe sobre el saber. Madrid: Cátedra.

Martín Algarra, M. (2009). La comunicación como objeto de estudio de la teoría de la comunicación. Anàlisi Quaderns De Comunicació I Cultura, (38), 151-172.

Martín Algarra, M., Torregrosa, M., \& Serrano, J. (2010). Un periodismo sin periodos: actualidad y tiempo en la era digital. In Periodística y web 2.0: hacia la construcción de un nuevo modelo. XII Congreso de la Sociedad Española de Periodística (pp. 1-14). Valencia: Universidad Cardenal Herrera.

Peters, J. D. (2003). Space, Time, and Communication Theory. Canadian Journal of Communication, 28(4), 397-411.

Putnam, R. D. (2003). El declive del capital social. Un estudio internacional sobre las sociedades y el sentido comunitario. Barcelona: Galaxia Gutemberg - Círculo de Lectores.

Ricoeur, P. (1987). Tiempo y narración I. Configuración del tiempo en el relato histórico. Madrid: Cristiandad.

Sánchez Capdequí, C. (2006). Flujos, elementos y formas sociales: La modernidad líquida a debate. Política y Sociedad, 43(2), 63-84. 
Scolari, C. (2013). Narrativas transmedia: cuando todos los medios cuentan. Barcelona: Deusto.

Starck, K., \& Kruckeberg, D. (2001). Public Relations and Community. In Handbook of Public Relations (pp. 51-59). Sage.

Thompson, J. B. (1998). Los media y la modernidad. Una teoría de los medios de comunicación. Barcelona: Piadós.

Vásquez Rocca, A. (2011). La Posmodernidad. Nuevo régimen de verdad, violencia metafísica y fin de los metarrelatos. Nómadas. Critical Journal of Social and Juridical Sciences, 29(1). 